\title{
Accounting for the Cyclical Dynamics of Income Shares
}

\section{Enchuan Shao and Pedro Silos}

\author{
Working Paper 2011-9 \\ March 2011
}

\begin{abstract}
Over the business cycle, labor's share of output is negatively but weakly correlated with output, and it lags output by about four quarters. Profit's share is strongly procyclical. It neither leads nor lags output, and its volatility is about four times that of output. Despite the importance of understanding the dynamics of income shares for understanding aggregate technology and the degree of competition in factor markets, macroeconomics lacks models that can account for these dynamics. This paper constructs a model that can replicate those facts. We introduce costly entry of firms in a model with frictional labor markets and find a link between the ability of the model to replicate income shares' dynamics and the ability of the model to amplify and propagate shocks. That link is a countercyclical real interest rate, a well-known fact in U.S. data but a feature that models of aggregate fluctuations have had difficulty achieving.
\end{abstract}

JEL classification: E3, E25, J3, E24

Key words: labor's share, frictional labor market, firm entry

A previous version of this paper circulated under the title "Firm Entry and Labor Market Dynamics," but it evolved into a completely different paper. The authors thank Nicole Baerg, Craig Burnside, Sanjay Chugh, Jason Faberman, Federico Mandelman, B. Ravikumar, Richard Rogerson, Gustavo Ventura, and participants at seminars at Duke University, the University of Maryland, the University of Iowa, Florida State University, the Federal Reserve Bank of Atlanta, and the Midwest Macroeconomics Meetings. The views expressed here are the authors' and not necessarily those of the Federal Reserve Bank of Atlanta or the Federal Reserve System. Any remaining errors are the authors' responsibility.

Please address questions regarding content to Bank of Canada, Currency Department, 234 Wellington Street, 0ttawa, Ontario, Canada K1A 0G9, 613-782-7926, eshao@bank-banque-canada.ca, or Pedro Silos, Federal Reserve Bank of Atlanta, Research Department, 1000 Peachtree Street, N.E., Atlanta, GA 30309-4470, 404-498-8630, 404-498-8956 (fax), pedro.silos@atl.frb.org.

Federal Reserve Bank of Atlanta working papers, including revised versions, are available on the Atlanta Fed's website at frbatlanta.org/pubs/WP/. Use the WebScriber Service at frbatlanta.org to receive e-mail notifications about new papers. 


\section{Introduction}

Most research in aggregate fluctuations has assumed factor income shares to be constant at all frequencies due to particular assumptions about technology and about the degree of competition in markets for goods and factors of production. The assumption of constant shares does not pass a test of casually inspecting the data, let alone analyzing it with sophisticated statistical tools. Understanding the time series behavior of income shares is critical for understanding the structure of aggregate technology and the behavior of factor markets. Despite the importance of income shares' behavior, macroeconomics lacks models that can quantitatively match the time series facts of income shares. This paper makes two contributions. First, it shows that existing models with time-varying income shares cannot account for their dynamics. Second, it constructs a model which can replicate, if not for all, many of the properties that describe the behavior of income shares.

During the post-war period, labor's share correlation with output is negative but weak; it lags output by about four quarters and is smoother than output. On the other hand, the profits' share is strongly pro-cyclical; it neither leads nor lags output; and its volatility is about four times that of output. As labor is arguably the most important factor of production, coupled with the fact that perfect competition in labor markets implies a tight link between wages and output, these facts have prompted previous studies to deviate from a Walrasian labor market. They have done so by specifying contractual arrangements between employers and employees that have broken the link between wages and the marginal product of labor. The goal was to match properties of labor's share over the business cycle. Examples of this line of work include Boldrin and Horvath (1995), Gomme and Greenwood (1995), and Danthine and Donaldson (1992).

Dispensing with a Walrasian framework is a characteristic of literature that features search and matching frictions in labor markets, e.g. Pissarides (1985). Our research falls 
within this framework. ${ }^{1}$ Although this literature has claimed success in matching some labor market business cycle moments, we show that the dynamics of income shares are completely at odds with the data. We link this failure to the typical assumption of free entry of firms, which leads to the asset value of a vacant position to be exactly zero at all frequencies. That free entry implies that the value of a vacant position equals zero can be seen easily from the textbook model of search and matching, for example Pissarides (2000). This model features firms posting vacancies to get matched to workers who are searching for jobs. If entry is free and any firm that wishes to do so can pay a vacancyposting cost and wait for this position to get filled, the present value of such a vacancy must be zero in equilibrium. If it were positive, firms would continue to post vacancies, lowering the probability that a given vacancy gets filled until its present value reaches zero.

We construct an environment in which the present value of a vacant position is always positive and endogenously varies over the business cycle. A vacancy has positive asset value because firms need to incur entry costs before they are allowed to post a vacancy, hire workers, and begin production. The equilibrium value of a vacancy is equal to the sunk cost, so that firms are indifferent between entering or staying out of the market. This equilibrium asset value is also time-varying. The reason: entrants rent factors of production to pay for the sunk cost and the efficiency of these factors is affected by the same shocks that generate aggregate fluctuations. As the prices and quantities of these factors vary with aggregate conditions, so do the expenditures that entrants undertake. In equilibrium, these expenditures must equal the capital value of a vacancy.

To some extent, our economy resembles a two-sector environment. The first sector produces goods and services that households consume, and the second sector produces services that entrants need to purchase. These purchases, in turn, allow entrants

\footnotetext{
${ }^{1}$ An alternative approach to study time-varying income shares is to introduce that time variation exogenously. This exogeneity still allows the researcher to analyze joint dynamics of those income shares with endogenous variables; output, for example. This is done by Young (2004).
} 
to access the goods-producing sector and profit from the sales of those goods. However, those two sectors compete for the same factors of production causing the dynamics of entrants to influence the dynamics of the demand, and hence prices, of those factors. Based on specific modeling assumptions described later in this paper, the behavior of these prices determines the dynamics of the value of a vacancy. We show that a reasonable parameterization of our environment can match the joint dynamics of labor's share, profits' share, and output. The model is consistent with the lagging behavior of labor's share, its weak correlation with output, and the hump-shaped response of labor's share to a shock to productivity. The model is also consistent with the strong correlation of output with profits' share and its lack of leading or lagging behavior. Matching the dynamics of income shares would be a Pyrrhic victory if it came at the expense of matching other business cycle moments. We show that this scenario is not the case. On the contrary, the very mechanism that improves the dynamics of income shares helps to amplify and propagate productivity shocks to the labor market, and the dynamics of investment and consumption are similar to existing models. Of course, our model works less well in some dimensions, and we report and discuss those factors as well. For instance, it is difficult to match the magnitude of empirical impulse response of labor's share to a productivity shock and, at the same time, match the low volatility of labor's share (relative to output).

We show that these results depend on one equilibrium outcome: that the value of a vacancy is countercyclical. In fact, parameterizations of our economy that yield a pro-cyclical capital value of a vacancy are inconsistent with the dynamics of income shares, and they feature virtually no amplification of shocks. Unfortunately, no good empirical data exist as counterparts to the asset value of a vacancy. Fortunately, in our model, the dynamics of the real interest rate essentially determine the dynamics of the value of a vacancy. However imperfect, we do have measures of real interest rates, and we show that the real interest rate is indeed countercyclical. The negative correlation between the real rate and output, and the fact that most models of economic fluctu- 
ations cannot replicate it, has been reported by King and Rebelo (1999). We provide alternative measures of the real rate and confirm previous findings. We emphasize that despite this counter-cyclicality of real rates, the dynamics of aggregate investment are almost identical to those of existing models.

\section{The Model Economy}

\subsection{Environment}

Our economy is populated by a large extended household comprised of a continuum of members of total mass equal to $\bar{N}$ and an infinite mass of firms.

Members in the household can either be employed or unemployed. Unemployed agents receive an unemployment benefit while they search for jobs with the hope of finding a job opportunity. This opportunity will allow them to enter into a relationship with a firm, to negotiate a contract that stipulates the retribution for their services, and to produce output during the following period. A fraction $N_{t}$ of employed agents works and gets paid the negotiated wage. Members of the household have preferences

over a sequence of a composite of goods over time, $\left\{C_{t}\right\}_{t=0}^{\infty}$. The per-period utility function is of the relative risk aversion class. The household's (expected) discounted lifetime utility as of time 0 is given by,

$$
E_{0} \sum_{t=0}^{\infty} \beta^{t}\left[\frac{C_{t}^{1-\sigma}}{1-\sigma}\right]
$$

where $\beta \in(0,1)$ is the discount factor and $\sigma>0$ is the coefficient of relative risk aversion. We assume that each firm produces a differentiated commodity. At each point in time, there is a subset of goods $X_{t} \subseteq X$ available to consumers, and the composite good is made up of commodities from that subset. The available set is time-varying as not all firms will produce every period. To aggregate over different commodities, we 
use a Dixit and Stiglitz (1977) aggregator:

$$
C_{t}=\left(\int_{x \in X_{t}}\left[c_{t}(x)\right]^{\frac{\gamma-1}{\gamma}} d x\right) \frac{\gamma}{\gamma-1}
$$

where $\gamma>1$ is the symmetric elasticity of substitution between commodities. If $p_{t}(x)$ is the price ${ }^{2}$ of product $x$, then the level of $c_{t}(x)$ chosen to minimize the cost of acquiring $C_{t}$ given prices $\left\{p_{t}(x)\right\}$ for all $x$ is:

$$
c_{t}(x)=\left(\frac{p_{t}(x)}{P_{t}}\right)^{-\gamma} C_{t},
$$

where $P_{t}$ is the cost of acquiring one unit of the composite good, or the price index ${ }^{3}$ :

$$
P_{t}=\left(\int_{x \in X_{t}}\left[p_{t}(x)\right]^{1-\gamma} d x\right)^{\frac{1}{1-\gamma}}
$$

Each firm uses capital and one unit of labor to produce its commodity. The job market in our economy is characterized by the existence of search and matching frictions (see Rogerson et al. (2005) for a survey of this literature). To hire a worker, a firm must post a vacancy and undertake a recruiting expense of $\omega$ per vacancy posted. Firms and potential workers match in a labor market, according to a constant-returnsto-scale matching technology $M(\bar{N}-N, V)$ given by:

$$
M(\bar{N}-N, V)=\frac{(\bar{N}-N) V}{\left((\bar{N}-N)^{\xi}+V^{\xi}\right)^{\frac{1}{\xi}}} .
$$

\footnotetext{
${ }^{2}$ As the subset of goods changes over time, it is more convenient to express this price in terms of "money" than to use any of the consumption goods as the numeraire. This is done for convenience only, and this "money" acts as a unit of account and is not valued for facilitating trades or for any other quality.

${ }^{3} \mathrm{P}$ can be obtained by solving the consumer expenditure minimization problem for constructing one unit of composite good:

$$
\begin{aligned}
P & =\min _{c} \int_{x \in X_{t}} p(x) c(x) d x, \\
\text { s.t. } \quad C & =\left(\int_{x \in X_{t}}[c(x)]^{\frac{\gamma-1}{\gamma}} d x\right)^{\frac{\gamma}{\gamma-1}}=1 .
\end{aligned}
$$
}


This matching function takes as inputs the total number of unemployed individuals who are searching, $\bar{N}-N$, and the total number of vacancies posted by firms, $V$. The output is a number of matches $M$. Denoting by $\theta$ the vacancies to unemployment ratio $\frac{V}{N-N}$, the probabilities that a vacancy gets filled, $q_{t}$, and that a worker finds a job, $f_{t}$ are given by ${ }^{4}$,

$$
\begin{aligned}
& q_{t}=\frac{M(\bar{N}-N, V)}{V}=\frac{1}{\left(1+\theta_{t}^{\tau}\right)^{\frac{1}{\xi}}} \\
& f_{t}=\frac{M(\bar{N}-N, V)}{\bar{N}-N}=\frac{\theta_{t}}{\left(1+\theta_{t}^{\tau}\right)^{\frac{1}{\xi}}} .
\end{aligned}
$$

A match between a firm and a worker results in a wage contract that specifies a wage $w_{t}(x)$, paid in exchange of labor services. We assume that firms and workers split the surplus from their relationship according to a Nash bargaining rule. We will explore this rule further after we have established the notation regarding workers' and firms' value functions. The relationship between a firm and a worker can break either because the firm exogenously ends production, which happens with probability $\tau$, or for any other reason, which happens at rate $s$.

Firms need to pay a sunk cost to begin the goods production process. ${ }^{5}$ Opening a firm or starting a new product variety needs $y^{E}$ effective units of capital, i.e. $y^{E}=Z_{t} K_{t}^{E}$. We assume the productivity process $Z_{t}$ is first-order Markov. Denoting by $r_{t}$ the rental rate of capital and noting that one unit of capital produces $Z_{t}$ units of the composite good, the sunk cost of entry is $\frac{r_{t} y^{E}}{Z_{t}}$ or $r_{t} K_{t}^{E}$ (in units of the composite consumption good). We denote the number of entrants, the number of firms that pay the sunk cost, by $N_{t}^{E}$.

Let us now describe the technology for producing the differentiated commodity, which, as the reader may recall, involves capital and labor. Denoting the firm's output

\footnotetext{
${ }^{4}$ We depart from the more frequent Cobb-Douglas specification for the matching function to bound the job-finding and vacancy-filling probabilities to be between 0 and 1 . This functional form was chosen by Den Haan, Ramey, and Watson (2000).

${ }^{5}$ Our approach for modeling firm entry follows Bilbiie, Ghironi, and Melitz (2006).
} 
of the differentiated product $x$ by $y_{t}^{c}(x)$, we can formally describe that technology as,

$$
y_{t}^{c}(x)=Z_{t} l_{t}(x)^{1-\alpha}\left(K_{t}^{c}(x)\right)^{\alpha}
$$

where $Z_{t}$ is the same random productivity process that determines the efficiency of capital when paying for the sunk cost, and $l_{t}(x)$ is the amount of labor employed by the firm, which is one if the firm produces and zero otherwise. The firm charges a price equal to $\rho_{t}(x)$, and its profits are given by $\pi_{t}(x)=\rho_{t}(x) y_{t}^{c}(x)-w_{t}(x)-r_{t} K_{t}^{C}(x)$.

Finally, the government plays a very limited role in our economy. Its task is solely to tax the household a lump-sum quantity and rebate it to the unemployed in the form of a benefit.

\subsection{Optimization and Equilibrium}

We restrict ourselves to a symmetric equilibrium, in which all goods-producing firms charge equal prices, $\rho_{t}(x)=\rho_{t}$; demand one unit of labor, which gets paid the same wage $w_{t}(x)=w_{t}$; and produce the same amount of output, $y_{t}^{c}(x)=y_{t}^{c}$. Given the CES structure of the consumption aggregate, the relative price $\rho_{t}$ that firms charge is given by ${ }^{6} N_{t}^{\frac{1}{\gamma-1}}$, and the per-firm profit is given by, $\pi_{t}=\rho_{t} y_{t}^{c}-w_{t}-r_{t} K_{t}^{c}$. The relevant state vector for the firm is the quadruplet $\left(K_{t}, N_{t}, V_{t}, Z_{t}\right)^{\prime}$ with $K_{t}=N_{t}^{E} K_{t}^{E}+N_{t} K_{t}^{c}$. To minimize notation, we write down value functions without being specific about their dependence on the state vector.

Households own a diversified portfolio of firms, and as a result, firms discount expected future flows taking into account the household's inter-temporal condition.

\footnotetext{
${ }^{6}$ Given that $p_{t}(x)=p_{t}$ and $\rho_{t}=\frac{p_{t}}{P_{t}}=\frac{p_{t}}{\left(\int_{x \in X_{t}}\left[p_{t}\right]^{1-\gamma} d x\right)^{\frac{1}{1-\gamma}}}$, the implication is that $\rho_{t}=\frac{p_{t}}{p_{t}\left(\int_{x \in X_{t}} d x\right)^{\frac{1}{1-\gamma}}}$ and as a result, $\rho_{t}=\left(\int_{x \in X_{t}} d x\right)^{\frac{1}{\gamma-1}}=N_{t}^{\frac{1}{\gamma-1}}$, as $N_{t}$ is the both the fraction of firms producing as well as the number of workers in the goods-producing sector by our assumption of one job per firm.
} 
Consequently, a firm's appropriate discount factor between periods $t$ and $t+1$ is,

$$
\Delta_{t+1}=\beta\left(\frac{C_{t+1}}{C_{t}}\right)^{-\sigma} .
$$

Let $Q_{t}$ denote the capital value of a vacancy and $J_{t}$ denote the capital value of a filled job. The following two recursive relationships must be satisfied:

$$
\begin{aligned}
Q_{t} & =-\omega+(1-\tau) E_{t} \Delta_{t+1}\left[q_{t} J_{t+1}+\left(1-q_{t}\right) Q_{t+1}\right], \\
J_{t} & =\pi_{t}+(1-\tau) E_{t} \Delta_{t+1}\left[(1-s) J_{t+1}+s Q_{t+1}\right] .
\end{aligned}
$$

Equation (9) states that the value of a vacancy (once the entry decision has been made) is the difference between two objects. The first object is the expected value of entering the labor market and trying to match with a worker. This matching happens with probability $q_{t}$, as long as the firm survives for one period, which happens with probability $1-\tau$. The second object is the vacancy cost $\omega$.

The interpretation of equation (10) is analogous: the value of a filled job is the profit flow $\pi$ plus the expected continuation value of the relationship between the firm and the worker. Conditional on the firm's survival, the relationship ends with probability $s$ and continues with probability $1-s$.

In equilibrium, the entry of firms occurs until the value of a vacancy is equal to the sunk cost,

$$
Q_{t}=r_{t} K_{t}^{E} .
$$

Due to entry costs, vacant jobs have positive value in equilibrium, which in turn leads firms to repost vacancies following separations. The following two equations give the laws of motion for the stock of employment and vacancies:

$$
\begin{aligned}
N_{t+1} & =(1-\tau)\left[(1-s) N_{t}+f_{t}\left(\bar{N}-N_{t}\right)\right], \\
V_{t+1} & =(1-\tau)\left[\left(1-q_{t}\right) V_{t}+s N_{t}\right]+N_{t}^{E} .
\end{aligned}
$$


Employment at time $t+1$ is the sum of matches $(1-s) N_{t}$ that were not destroyed either by the death of a firm or any other form of separation, and the newly-formed matches $f_{t}\left(\bar{N}-N_{t}\right)$ from a previous pool of unemployed people. The total number of vacancies in the economy, given by equation (13), is equal to vacancies that did not get filled in the current period, $\left(1-q_{t}\right) V_{t}$ plus the number of separated matches $s N_{t}$. Of course, we need to include the fraction of firms which continue operating for at least one more period. Finally, we need to add to reach the total, the number of newly created firms $N_{t}^{E}$, each of which posts a vacancy. Both employment and vacancies are predetermined variables.

The household's problem is relatively straightforward. Given its current period resources, it chooses consumption and investment to maximize the expected discounted value of lifetime utility. In addition to wage income and unemployment benefits, the household gets interest from renting capital as well as a pay-out from its diversified ownership stake in firms. The aggregate dividends firms pay out equal to $d_{t}=$ $N_{t} \pi_{t}-\omega V_{t}-Q_{t} N_{t}^{E}$. Finally, the household pays a lump-sum tax $T_{t}$, which the government uses to finance its unemployment benefits program. Denoting by $W_{t}$ the household's value function at time $t$, the optimization problem is expressed as:

$$
W_{t}=\max _{C_{t}, I_{t}} \frac{C_{t}^{1-\sigma}}{1-\sigma}+\beta E_{t} W_{t+1}
$$

subject to

$$
\begin{aligned}
C_{t}+I_{t} & =b\left(\bar{N}-N_{t}\right)+w_{t} N_{t}+r_{t} K_{t}+d_{t}-T_{t}, \\
K_{t+1} & =(1-\delta) K_{t}+I_{t} .
\end{aligned}
$$

The optimal inter-temporal condition is:

$$
\beta E_{t}\left[\left(\frac{C_{t+1}}{C_{t}}\right)^{-\sigma}\left(r_{t+1}+1-\delta\right)\right]=1 .
$$


As discussed in the previous section, wages for employed workers are the result of Nash bargaining between each worker/firm pair. The surplus of the match for the household is captured by the change in welfare derived from having a marginal unemployed person who is then hired. This change is given by $\frac{\partial W_{t}}{\partial N_{t}}$, which in units of the consumption good is $\frac{\partial W_{t}}{\partial N_{t}} C_{t}^{\sigma}$. The surplus for the firm is given by $J_{t}-Q_{t}$, the difference between the value of a filled job and the value of a vacancy. The Nash bargaining solution when the firm's bargaining parameter is given by $\phi$ satisfies the following surplus-splitting rule:

$$
\frac{J_{t}-Q_{t}}{1-\phi}=\frac{C_{t}^{\sigma} \frac{\partial W_{t}}{\partial N_{t}}}{\phi}
$$

which yields the following equation for wages:

$$
w_{t}=(1-\phi) b+\phi\left(\rho_{t} Z_{t}-r_{t} K_{t}^{C}+\omega\right)-\phi\left(1-\theta_{t}\right)\left(\omega+Q_{t}-(1-\tau) E_{t} \beta \Delta_{t+1} Q_{t+1}\right) .
$$

To better understand the analysis on the dynamics of income shares that follows, let us first define these shares. Total output $y_{t}$ can be decomposed in three elements: payments to capital, labor, and equity-holders. As a result we can re-write output as,

$$
y_{t}=r_{t} K_{t}+N_{t} w_{t}+N_{t} \pi_{t}{ }^{7}
$$

Labor's share is then defined as $\frac{w_{t} N_{t}}{y_{t}}$, and profits' share is defined as $\frac{N_{t} \pi_{t}}{y_{t}}$.

We can now describe a symmetric equilibrium for our economy. It is a sequence of prices $\rho_{t}, w_{t}, r_{t}$; a sequence of aggregate quantities $K_{t}, C_{t}, N_{t}, V_{t}, N_{t}^{E}, \pi_{t}$; and a sequence of value functions $Q_{t}, J_{t}, W_{t}$ such that for any time period $t$, the following conditions hold:

1. (Household Optimization) Given prices $\rho, w, r$, the household's optimization results in decision rules for $C_{t}$ and $I_{t}$ and the value function $W_{t}$.

\footnotetext{
${ }^{7}$ To be clear about how we reach this expression, recall that profits are defined by $\pi_{t}=\rho_{t} y_{t}^{c}-r_{t} K_{t}^{c}-$ $w_{t}$. Total output $y_{t}$ is defined as the sum of output in the two sectors: $y_{t}=r_{t} K_{t}^{E} N_{t}^{E}+\rho_{t} y_{t}^{\mathcal{C}} N_{t}$. Simple substitution yields $y_{t}=r_{t} K_{t}^{E} N_{t}^{E}+N_{t}\left(\pi_{t}+r_{t} K_{t}^{C}+w_{t}\right)=r_{t} K_{t}+N_{t} \pi_{t}+N_{t} w_{t}$.
} 
2. (Factor Market Clearing) The interest rate $r_{t}$ equates the capital demanded by new entrants $N_{t}^{E}$ and current producers $N_{t}$ to that supplied by the household, and the wage $w$ satisfies the Nash bargaining solution given by equation (19).

3. (Goods Market Clearing) $C_{t}+I_{t}+\omega V_{t}=\rho_{t} y_{t}^{c} N_{t}$.

4. (Firm's Optimization) Given the demand for a differentiated commodity given by equation (3), $\rho_{t}$ is the profit-maximizing price for the monopolist. Aggregate labor demand and vacancies posted by all firms, $N_{t}^{E}, N_{t}$ and $V_{t}$, satisfy equations (12) and (13), and the vacancy and filled position values satisfy equations (9) and (10).

5. (Entry Condition) $Q_{t}=r_{t} K_{t}^{E}$.

6. (Government) The government satisfies its budget constraint: $b\left(\bar{N}-N_{t}\right)=T$.

\subsection{Calibration}

We calibrate the model to the monthly frequency by assigning values to parameters, so that steady-state moments in the model match those observed in U.S. data. The risk aversion coefficient $\sigma$ is set to 1.5 , well within the range of values typically used in studies of aggregate fluctuations. The discount factor $\beta$ is set to $0.99^{\frac{1}{3}}$, implying a steady-state interest rate equal to $4.1 \%$ per annum.

We assume that the productivity process $Z_{t}$ follows an $\mathrm{AR}(1)$ process with persistence parameter $\rho_{z}$ and a zero-mean normally distributed shock with variance $\sigma_{\epsilon}^{2}$. We set $\rho_{z}=0.964$ and $\sigma_{\epsilon}=0.0052$, which are consistent with the cyclical persistence and variance in the observed Solow residual. ${ }^{8}$ Lacking direct evidence on a reasonable value for the workers' bargaining parameter $\phi$, we set it equal to 0.5 to make our results comparable to the existing literature (e.g. Shimer (2005)).

\footnotetext{
${ }^{8}$ In the presence of monopolistic competition, variations in the Solow residual cannot be directly associated with productivity of factors of production. The computation of the Solow residual assumes perfect competition and only then can that association be made. For an extensive discussion, see Hornstein (1993).
} 
We calibrate the exit probability $\tau$ and the separation rate $s$ following a procedure similar to that of Den Haan et al. (2000). Let $\Sigma$ be the total job separation rate caused either by a firm's death or any other cause. The rate at which firms exit the market and do not repost vacancies is $\tau$, while $(1-\tau) s$ is the rate at which workers separate from firms but where firms repost vacancies immediately. Hence, $\Sigma=\tau+(1-\tau)$ s. The fraction of vacancies that are reposted immediately after separations is then $\frac{(1-\tau) s}{\Sigma}$. Denote this quantity by $\Omega$. Note also that $\Sigma N$ gives the total flow out of employment, and as a result, $\Omega q \Sigma N$ gives the total number of posted vacancies filled. If we subtract the number of posted vacancies that are filled from the total flow out of employment, we get the steady-state mass of jobs that is destroyed permanently: $\Sigma N-\Sigma N \Omega q=$ $\Sigma N(1-\Omega q)$. In a steady state, job destruction must equal job creation. The empirical evidence described by Shimer (2005) sets $\Sigma$ equal to 0.1 at the quarterly frequency, which implies $1-(1-0.1)^{\frac{1}{3}}=0.035$ at the monthly frequency. Therefore,

$$
\Sigma=(1-\tau) s+\tau=0.035
$$

Davis et al. (1996) report that the job-creation-to-employment ratio in the manufacturing sector is 0.052 quarterly, which implies a value of 0.018 at the monthly frequency. Given a value of $q=0.802$ per month,

$$
\frac{\text { Job Creation }}{\text { Employment }}=\frac{\Sigma N(1-\Omega q)}{N}=0.018
$$

From equations (20) and (21) we can solve for $s=0.021$ and $\tau=0.014$.

Consistent with estimates reported by Basu and Fernald (1997), we set $\gamma=11$, which implies a markup of 10 percent. Changing the total mass of workers $\bar{N}$ only amounts to changing the levels, i.e., the scale of output and the mass of employment, etc. But the unit-free ratios (e.g., unemployment rate, v-u ratio, and consumptionoutput ratio etc.), are unaffected. Therefore, a choice of $\bar{N}$ does not affect any of 
the second moments and the impulse responses. We choose $\bar{N}>1$ so that the monopolist's price is larger than the resulting price if markets are competitive, given by $\lim _{\gamma \rightarrow \infty} N_{t}^{\frac{1}{\gamma-1}}=1$.

We are left with six parameters to calibrate: $\left(b, y^{E}, \delta, \omega, \xi, \alpha\right)$. To do so, we choose six additional moments that the model needs to match in its steady state. Based on his own calculations, Shimer (2005) documents that the monthly job finding rate is 0.45. Blanchard and Diamond (1989) argue that vacancy postings have an average of 3 weeks, which implies that the vacancy filling rate is $1-(1-1 / 3)^{4}=0.802$ per month. Note that the steady state value of market tightness can be written as $\theta=\frac{f}{q}=0.56$. We choose to match the aggregate capital to aggregate output ratio, and we set it to a value of 36, which implies a value of 3 at the annual frequency. We set total recruiting costs as a fraction of GDP, given by $\omega V / Y$, to 0.015 . A controversial choice is that of the value of the unemployment benefit $b$. Much of the literature argues that the value of non-work activities is far below what workers actually produce on the job. However, calibrations such as Hagedorn and Manovskii's (2007) claim success in terms of the cyclical properties of the model when the outside option for workers is very close to their productivity. Under the interpretation of $b$ as purely monetary unemployment benefits, we set $b$ so that the steady-state replacement ratio $b / w$ is 0.42 , as in Shimer (2005) and Gertler and Trigari (2006). Finally, we want to match an additional moment in the steady-state value for labor's share, which is 0.60 for the sample under consideration. In conclusion, to assign values to the vector of parameters $\left(b, y^{E}, \delta, \omega, \xi, \alpha\right)$, we choose the following six moments: $f=0.45, \theta=0.56, \omega V / Y=0.015, K / Y=36$, $b / w=0.42$, and $w N / Y$.

We summarize our parameterization in Table 2.1.

\footnotetext{
${ }^{9}$ As the steady-state value of $N^{E}$ is small, one needs a high value of $y^{E}$ to match the value for the capital-to-output ratio found in the data.
} 
Table 2.1: Summary of Parameterization

\begin{tabular}{ccc} 
Parameter & Value & Target/Source \\
\hline \hline$\sigma$ & 1.500 & Prev. work \\
$\phi$ & 0.500 & Prev. work \\
$\rho_{z}$ & 0.964 & NIPA \\
$\sigma_{z}$ & 0.005 & NIPA \\
$\tau$ & 0.014 & Job Creation $=0.018$ \\
$s$ & 0.021 & $\sum=0.035$ \\
$\gamma$ & 11 & $10 \%$ markup \\
$\beta$ & $(0.99)^{\frac{1}{3}}$ & $r=4.1 \%$ \\
$\delta$ & 0.002 & $K / Y=36$ \\
$b$ & 0.380 & $b / w=0.42$ \\
$y^{E}$ & $3,140^{9}$ & $w V / Y=0.015$ \\
$\omega$ & 0.516 & $f=0.45$ \\
$\xi$ & 1.551 & $\theta=0.561$ \\
$\alpha$ & 0.02 & $w N / Y=0.60$ \\
\hline
\end{tabular}

\section{Results}

\subsection{The Cyclical Behavior of Labor's and Corporate Profits Shares}

Having assigned parameter values to the model, we solve it, simulate it, and judge its implications against U.S. data. Our solution technique is standard: we approximate the true solution by a first order expansion around the model's deterministic steady state. Since the calibration is done at the monthly frequency, we transform the model's output by aggregating its "monthly" data into "quarterly" data by taking three-month averages. We transform the model's output and U.S. data in the same way: we detrend them by taking logs and applying a Hodrick-Prescott filter. ${ }^{10}$

To construct the labor's and profit shares, we proceed as follows. To measure the share of income that goes to labor, we add total private salaries and wages, supplements to salaries and wages, and all of proprietors' income. We divide this sum by national income. To compute profits' shares, we take corporate profits and divide them by national income. Our sample starts in 1951 (1st quarter) and ends in 2003 (fourth

\footnotetext{
${ }^{10}$ The HP smoothing parameter we use is 1,600 , a standard choice when using quarterly data.
} 
quarter).

Figure 1 shows correlations between real GDP and labor's share with different leads and lags for the U.S. economy. Correlations are not strong, the maximum is about 0.40 , and the contemporaneous correlation is (significantly) smaller than the correlation between output and the labor's share with a four-period lead. Consequently, labor's share lags real GDP because its correlation coefficient with output is highest after four quarters. Labor's share is countercyclical but very weakly so: the contemporaneous correlation is -0.28 , and the 5th percentile for the sample distribution of that correlation is -0.15 . Figure 2 shows a similar picture for the (corporate) profits' share which shows stronger cyclical dynamics than the labor's share. Also, it is procyclical, and shows no leading or lagging pattern.

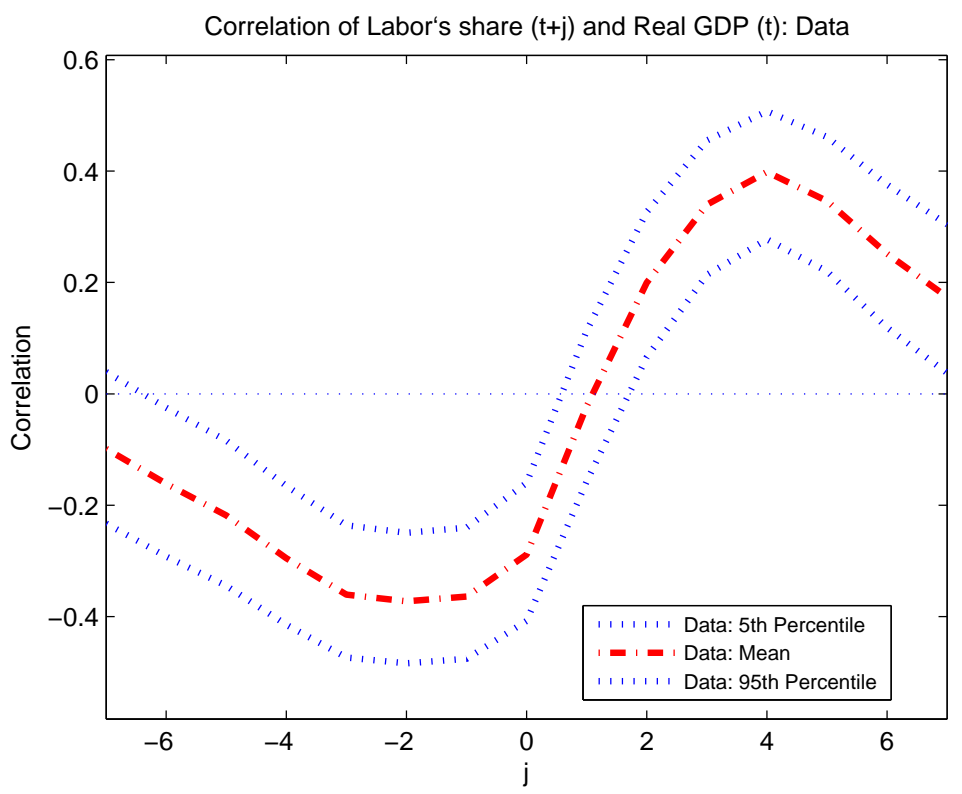

Figure 1: Correlations between Real Gross Domestic Product and (led and lagged) Labor's Share of Real GDP - US Data 1951-2003.

How well does the model of costly firm entry match these patterns compared to standard models where firm entry is free? Let's begin with labor's share. ${ }^{11}$ Figure

\footnotetext{
${ }^{11}$ All results presented in the paper have CES preferences, see equation (2). This specification features constant markups. To introduce time-varying markups we changed the utility function to be of the translog type, see Feenstra (2003). The results are similar to the baseline CES case and they are available
} 
3 displays the empirical cross-correlations, the same values as Figure 1 represented by the dotted and dash-dotted lines, along with the cross-correlations from the entry model (labeled "Model" in the figure and represented by the circled-thick line). Labor's share in the model matches the patterns observed in the data remarkably well. The contemporaneous correlation is weak with a value of -0.15 and well within the error bounds provided for the empirical correlations.

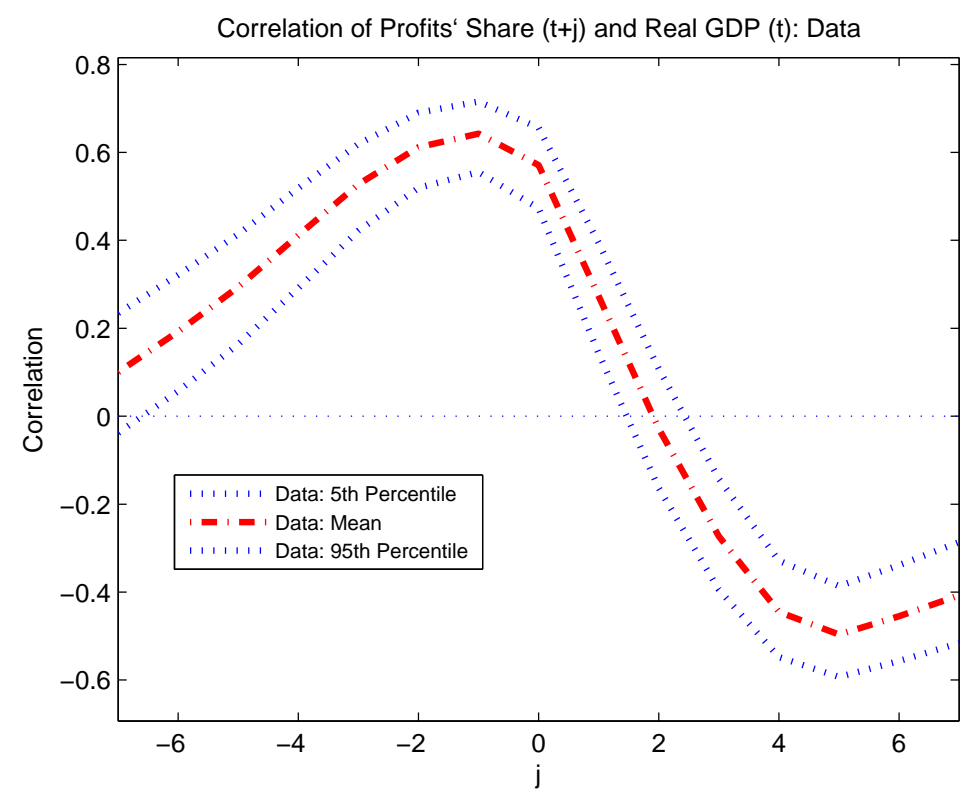

Figure 2: Correlations between Real Gross Domestic Product and (led and lagged) Profits' Share of Real GDP - US Data 1951-2003.

The correlations with one lead and one lag quantitatively match their empirical counterparts, and only correlations at higher leads and lags are somewhat stronger than those found in the data. Most importantly, the model gets the lagging pattern of labor's share right: after an increase in output, labor's share shows the largest increase four quarters later without a large contemporaneous effect. Figure 4 shows the analog to Figure 3 for the profits' share rather than for labor's share. The figure shows that the model with costly entry matches well with the correlations at several leads and lags of the profits' share and output. In fact, all correlations are within the error bounds conupon request. 
structed for the empirical point estimates. Before we explain the pattern of correlations in the model with costly entry, let's compare it to a benchmark model: the model with free entry. Readers can think of this model as a version of the one solved in Shimer (2005), to which we add capital. We model it in discrete time, and to improve its fit of labor market business cycle dynamics, we calibrate it along the lines of Hagedorn and Manovskii (2009). ${ }^{12}$ Figure 5 adds to Figure 3 the patterns of correlations between output and labor's share computed from the model with free entry. The figure shows how the labor's share in the free entry model is strongly countercyclical. Although it may not be apparent from a quick glance at the graph, the value of the contemporaneous correlation is -0.95 , as opposed to -0.15 in the costly entry model and -0.20 in the data. These differences are large. The performance of the free entry model regarding the profits share is better, as one can see in Figure 6, but considerably worse than the costly entry model. In the free entry model, the strong cyclicality in the profits share, which is consistent with the data, comes at the expense of a strong cyclicality in the labor's share, which is not. De-linking the cyclical dynamics of the two shares, in the sense of generating weak correlations between labor's share and output and strong correlations between the profits' share and output, is something our model is able to achieve.

The strong countercyclicality of labor's share generated in the free entry model is caused by the relatively larger response of output to a rise in productivity. Matching frictions prevents employment from adjusting immediately to a productivity shock, a feature of all models presented in this paper. In the free entry model, both wages and output respond rapidly to a change in productivity, but output responds relatively stronger. As a result, labor's share falls sharply (relative to its steady state value) but as employment rises in subsequent periods, labor's share rises as well. This movement explains the strong negative contemporaneous correlation and the mildly positive correlation of output with the value of labor's share three or four quarters later.

\footnotetext{
${ }^{12}$ We describe with more detail the structure and calibration of the free-entry model in the Appendix.
} 


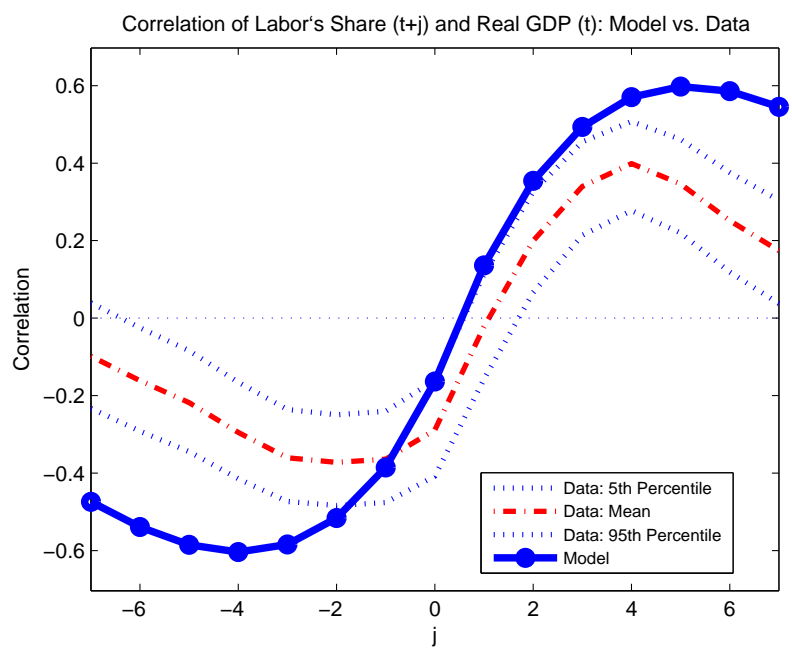

Figure 3: Correlations between Real Gross Domestic Product and (led and lagged) Labor's Share of Real GDP - US Data 1951-2003 (dashed-dotted lines) and Costly Entry model (circled line)

To understand the dynamics in the costly-entry model, remember that output $y_{t}$ is equal to,

$$
\rho_{t} y_{t}^{c} N_{t}+r_{t} K_{t}^{E} N_{t}^{E}=\rho_{t} y_{t}^{c} N_{t}+Q_{t} N_{t}^{E} .
$$

In other words, total output is the sum of income in two "sectors": the commodity producing sector, $\rho_{t} y_{t}^{c} N_{t}$, and the "start-up" sector, $r_{t} K_{t}^{E} N_{t}^{E}$. The joint dynamics of both sectors determine the dynamics of total output. In the case of a positive productivity shock, an immediate response is a drop in $K^{E}$, the "per-start-up" amount of capital, as $y^{E}$ is constant. The number of entrants $N^{E}$ rises, as the present value of profits is now higher. The remaining key variable determining the behavior of output in the "start-up" sector is therefore the interest rate, $r_{t}$. The equilibrium interest rate is determined by the relative demand and supply of capital in the two sectors. Total capital, $K_{t}=N_{t}^{E} K_{t}^{E}+N_{t} K_{t}^{c}$, is a predetermined variable but the economy can reallocate it intratemporally between the two sectors. The technology of the goods producing sector being Cobb-Douglas forces interest rates to rise in the face of a positive technology shock. This result is standard in models of economic fluctuations with Cobb-Douglas technol- 
ogy and the culprit for the strong procyclicality of real interest rates in the real business cycle literature. What happens in the "start-up" sector? Because $K_{t}^{E}$ falls when $Z_{t}$ rises, the demand for capital by any given entrant is lower, forcing interest rates to drop. In summary, the behavior of interest rates in the face of an increase in productivity is the result of two counteracting forces. On the one hand, technology in the goods producing sector pulls interest rates upward when productivity rises, but on the other hand, it lowers the amount of capital an entrant needs, lowering the demand for capital and pulling rates downward. Using the calibration described previously, interest rates are countercyclical. This drop in interest rates is responsible for the more muted response of output (relative to that of wages) in the costly entry model. In turn, this drop also dampens the negative response of labor's share to an increase in productivity.

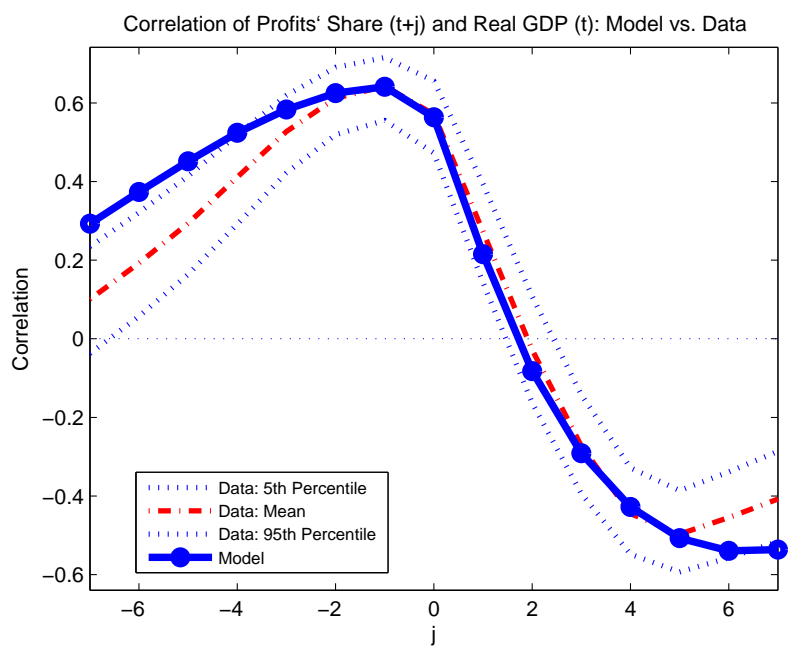

Figure 4: Correlations between Real Gross Domestic Product and (led and lagged) Profits' Share of Real GDP - US Data 1951-2003 (dashed-dotted lines) and costly entry model (circled line).

The evolution of interest rates helps explain the more muted response of output in the costly entry model. However, this factor is only part of the story when it comes to explaining the different dynamics of labor's share in the two models. The existence of entry costs may, depending on parameter values, make the response of employment (and wages) persist over time. This persistence is due to resources in the start-up sector competing with those in the goods-producing sector. As a result, entrants may find it 
optimal to delay their entrance so more capital can be used for producing goods when productivity is high. This delayed response raises wages and employment for several quarters, increasing the numerator in the expression for labor's share, explaining the lagging behavior, that is, the high positive correlation between output and the value of labor's share four quarters later.

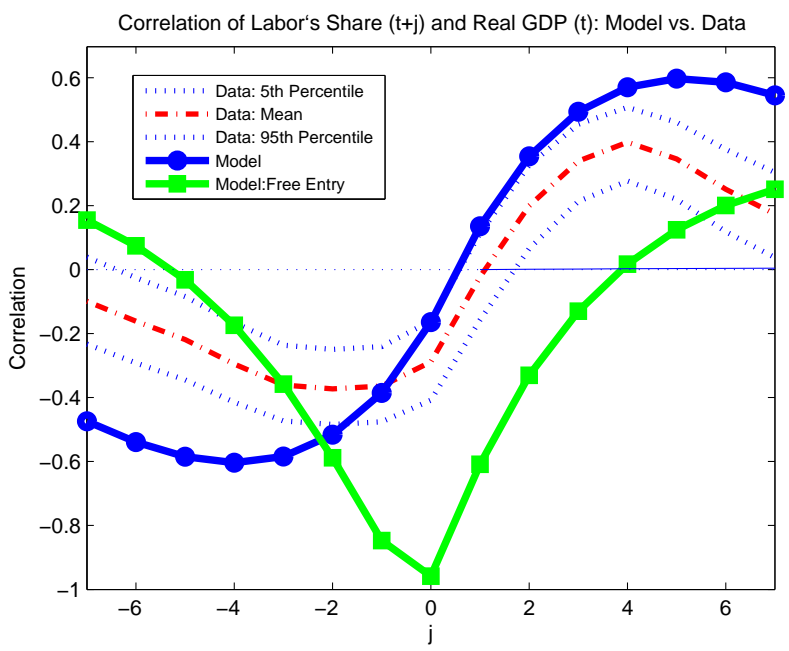

Figure 5: Correlations between Real Gross Domestic Product and (led and lagged) Labor's Share of Real GDP - US Data 1951-2003 (dashed-dotted lines), costly entry model (circled line) and free entry model (squared line).

So far, we have seen that the joint dynamics of firm entry, the asset value of a vacant position, and the interest rates are important for understanding the dynamics of income shares. In truth, distinguishing between the dynamics of the value of a vacancy and interest rates in the costly entry models is unnecessary. Recall that the value of a vacancy $Q_{t}$ is equal to $r_{t} K_{t}^{E}$. In both costly entry models, $K_{t}^{E}$ displays exactly the same dynamics, again because $y^{E}$ is a constant and $Z_{t}$ is exogenous. So the behavior of $Q$ is essentially driven by the behavior of interest rates, $r$. But let us return to understanding the dynamics of income shares by showing through a different channel that it is indeed the joint dynamics of entry and real interest rates that are crucial. They are crucial both for the weak low contemporaneous correlation between output and the labor's share and the lagging pattern of the cross-correlations. 
This different channel is running an experiment that involves making firm entry less attractive by lowering the efficiency of the matching technology. This efficiency is represented by $\xi$, which we set now to a value of 0.38 . (It was 1.551 before). The result is two effects on firm entry. First, it lowers the steady-state value of entrants. As matching becomes more difficult, the probability of matching to a worker decreases. This decrease lowers the prospects of making any profits, leading to a lower level of entrants in equilibrium. Second, firm entry is less persistent. To understand this second effect, assume first a positive shock to productivity from the steady state. If matching efficiency is low, firms need to enter relatively early to be able to match with workers and still take advantage of the higher productivity. Consequently, firm entry concentrates in the first few periods after the shock. The early concentration of entrants results in a relatively high demand for capital in the "start-up" sector, which prevents interest rates from falling. As a result, the response of output is closer to that of the free entry model, response that implies a larger drop in labor's share. Because entry is not delayed, neither is the response of wages and employment as persistent. Therefore, the numerator of labor's share fails to rise much in subsequent periods, reducing the correlation between output and labor's share after four quarters. Figure 7 shows the disappearance of the lagging behavior and the appearance of a strong countercyclicality of labor's share. That figure shows that the contemporaneous correlation between the labor's share and output is close to -1. Profits shares also display similar dynamics to the free entry model (see Figure 8). To re-iterate, these differences arise because of changing dynamics in firm entry, interest rates, and he asset value of a vacant position. They do not arise because of differences in the level of sunk costs $y^{E}$, which has remained at the value calibrated in the previous section throughout the exercise of lowering $\xi$.

The previous figures, and the intuition behind them, make it clear that the behavior of entrants, the behavior of the value of a vacancy, and the dynamics of interest rates are important for understanding the dynamics of income shares. To further validate our 


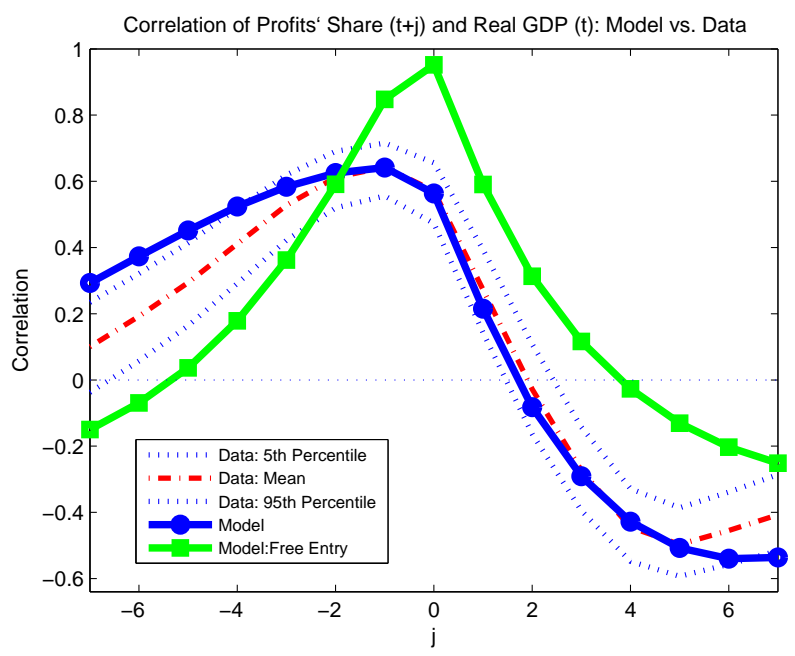

Figure 6: Correlations between Real Gross Domestic Product and (led and lagged) Profits' Share of Real GDP - US Data 1951-2003 (dashed-dotted lines), costly entry model (circled line) and free entry model (squared line).

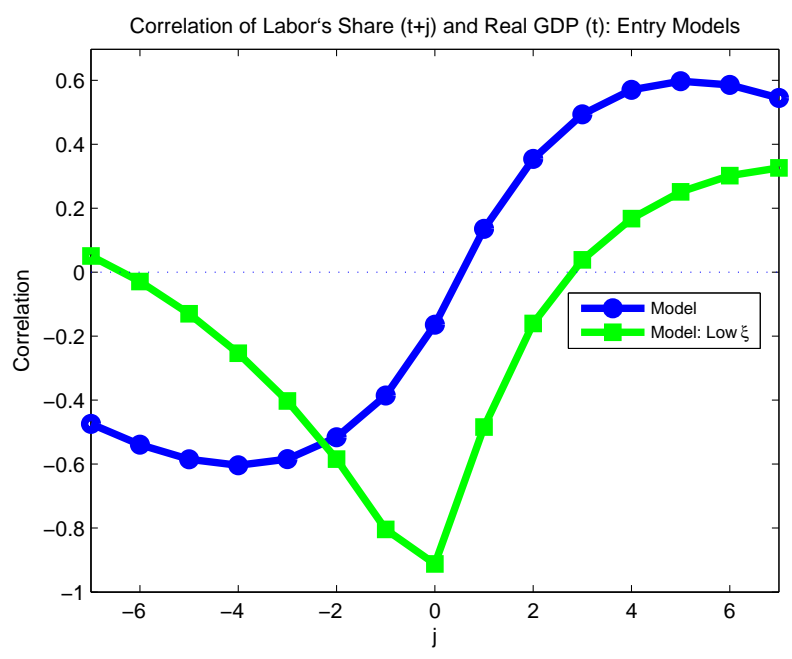

Figure 7: Correlations between Real Gross Domestic Product (output) and (led and lagged) Labor's Share of output - costly entry model (circled line) and Low $\xi$ model (squared line).

model we need more evidence. To that end, we show that the dynamics of real interest rates in the data are consistent with the costly entry model at the expense of the other two. To get an empirical counterpart to interest rates in the theoretical models, we first obtain quarterly measures of nominal yields from corporate bonds (Baa-rated). We restrict the sample as the same as that used to compute correlations of income shares: 1951:Q1-2003:Q1. To transform those nominal yields into real yields, we subtract the 


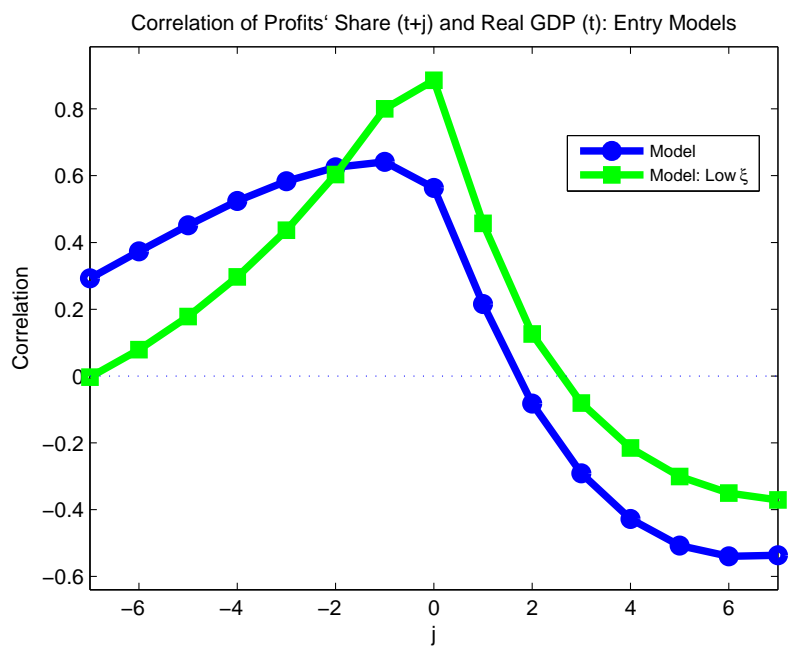

Figure 8: Correlations between Real Gross Domestic Product (output) and (led and lagged) Profits' Share of output - costly entry model (circled line) and Low $\zeta$ model (squared line).

inflation rate for that quarter (annualized, because yields are annualized as well). ${ }^{13}$ The first row of Table 3.1 shows the correlation at the quarterly frequency of real interest rates and output in the data and in the three model economies. ${ }^{14}$ The correlation between the real interest rate and output in the data is $-0.348 .^{15}$ Both the free entry model and the costly entry model with low $\xi$ feature pro-cyclical interest rates with correlations close to 1 (0.972 and 0.982 respectively). On the other hand, the Costly Entry model features countercyclical interest rates. The correlation of these with output has a value of -0.272 , remarkably close to that observed in the data. ${ }^{16}$

Given the correlations of interest rates and output in the two costly entry models, it is not surprising that the correlation between the value of a vacancy is negative in the costly entry model and positive in the costly entry model with low $\xi$. Given the tight link in the model between $Q_{t}$ and $r_{t}$, even though we lack empirical measures of the

\footnotetext{
${ }^{13}$ We take current inflation as a reasonable forecast of inflation in the next three months. In the shortrun, this "random-walk" forecast works remarkably well (see Stock and Watson (1999b)).

${ }^{14}$ We de-trend real interest rates, both in the data and in the model economies, by computing the percentage deviation relative to steady state.

${ }^{15}$ Stock and Watson (1999a), using expected inflation from a VAR and the yield on T-bills, report a correlation of -0.35 .

${ }^{16}$ Gomme, Ravikumar, and Rupert (2010) find a weaker, but negative nevertheless (-0.13), correlation between output and after-tax returns in the SP500 stock market index.
} 
Table 3.1: Correlations between $y_{t}$ and $r_{t}, Q_{t}$ and $N_{t}^{E}$ : Data vs. Models

\begin{tabular}{ccccc}
\hline \hline & US Data & Costly Entry & Costly Entry (low $\tilde{\xi})$ & Free Entry \\
\hline $\operatorname{Corr}(y, r)$ & -0.348 & -0.272 & 0.982 & 0.972 \\
$\operatorname{Corr}(y, Q)$ & N/A & -0.664 & 0.795 & N/A \\
$\operatorname{Corr}\left(y, N^{E}\right)$ & 0.510 & 0.983 & 0.992 & N/A \\
\hline \hline
\end{tabular}

value of a vacancy, the model shows that the real interest rate is an excellent proxy. This proxy strengthens the hypothesis that the costly entry model is a good representation of the data.

Finally, to the best of our knowledge, no good measures of firm entry exist. We have taken one used by Bilbiie, Ghironi and Melitz (2005), in which they report a correlation of 0.510 with output (see their Figure 2). However, even if good measures of entry existed, this variable does not allow one to distinguish among the two costly entry models. The reason is that firm entry is procyclical and similar in magnitude in both models.

We now provide more evidence supporting the costly entry environment. We do so by looking at yet another feature of the data that existing models have difficulty replicating. Ríos-Rull and Choi (2008), building on the empirical analysis of Ríos-Rull and Santaeulalia-Llopis (2008), note that an empirical regularity of labor's share is at odds with US data in a large class of models. This regularity pertains to the response of labor's share to a productivity shock. To replicate their results, we construct a series for the Solow residual, and we use our measure of labor's share described above to follow the same methodology for computing that response. Consequently, we fit a bivariate VAR to these two series and identify a "fundamental" innovation to the technology process, assuming that labor's share fails to affect technology contemporaneously. Specifically we assume that the "structural" representation of the reduced-form VAR takes the following form,

$$
l s h_{t}=\alpha_{0}+\beta_{0} z_{t}+\alpha_{11} l s h_{t-1}+\alpha_{12} z_{t-1}+\epsilon_{l s h, t}
$$




$$
z_{t}=\alpha_{1}+\alpha_{21} l s h_{t-1}+\alpha_{22} z_{t-1}+\epsilon_{z, t}
$$

Figure 9 shows the response of labor's share to a one-standard deviation innovation in the technology process. Labor's share falls contemporaneously and starts rising one quarter after the shock. The rise continues for about five years, after which labor's share slowly returns to its steady-state level.

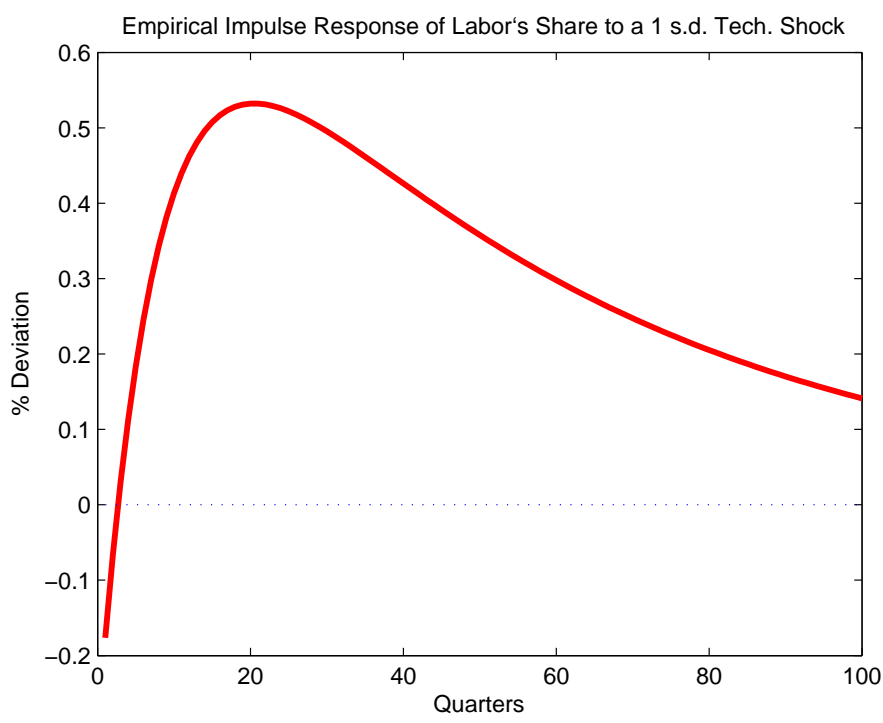

Figure 9: Response of labor's share to a one standard deviation (orthogonalized) innovation to technology.

In addition to the "over-shooting" property, the two most noticeable features are the magnitude of the rise (significantly above the steady-state level) and the persistence of the response. In their quest for models that can match this feature of the data, RíosRull and Choi (2008) focus on a family of search and matching models of the labor market in which wages are the result of Nash bargaining. The standard model (i.e. Pissarides (1985) or Shimer (2005)) matches only the initial drop. After the first period, the response of labor's share is rather muted when compared to the data. It never rises much above its steady-state level and it displays virtually no persistence. This pattern remains true even when the model is calibrated to match the volatility of the vacanciesto-unemployment ratio observed in the data. As our framework belongs to the same 
family of search and matching models, we perform a similar analysis.

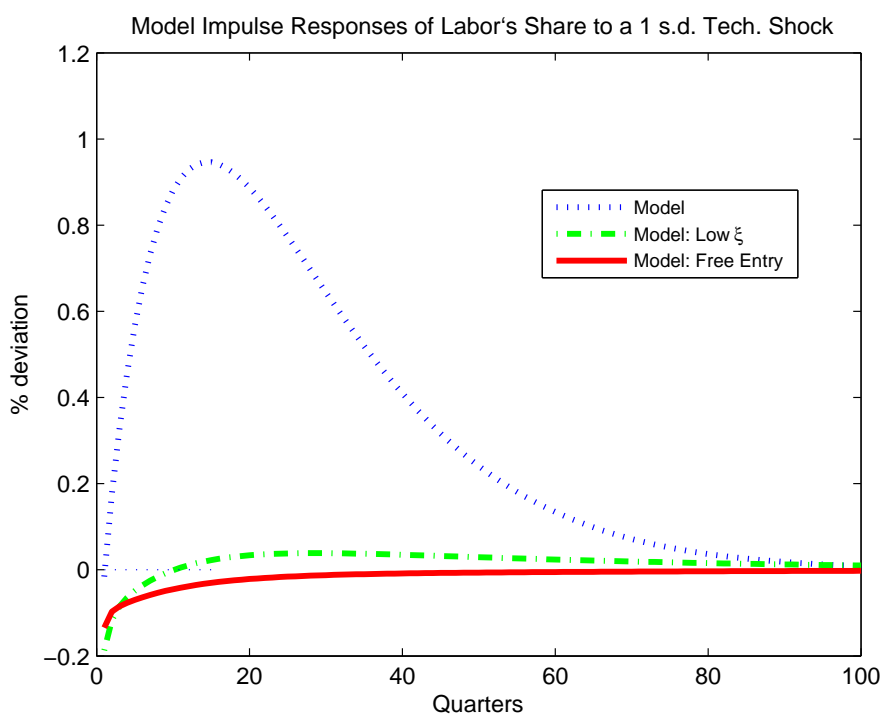

Figure 10: Response of labor's share to a one standard deviation (orthogonalized) innovation to technology in our three model economies.

Figure 10 displays the response of labor's share in the same three models discussed above: the costly-entry model, the free entry model, and the costly-entry with low matching efficiency. We compute the quarterly response as the three-month average of the original monthly response. The first model, labeled "model", is the costly-entry model parameterized according to Section 2.3. The second, labeled "model: low $\xi$, is the costly-entry model with a lower matching efficiency obtained through a lower value for $\xi$. Finally, the third model is the free entry model described briefly above and in more detail in the appendix. The costly entry model features a labor's share that initially falls, rising significantly above its steady-state value until its peak five years after the impulse. It also persists at above-steady-state levels for a long period of time. The intuition behind these results follows from the general discussion of the cyclical dynamics of income shares. The sunk costs of entry introduce sluggishness in the decision of firms, generating persistence and helping to achieve the longer duration in response to a shock. Labor's share rises because output in the setup-sector falls initially, relative to its long-run value. Consistent with the plots shown for correlations 
of labor's share and output, the responses in the free entry model and the costly entry model with low matching efficiency are close and do not match the data well.

\subsection{Other Business Cycle Dynamics}

After explaining the mechanism by which the costly entry model generates dynamics of income shares that roughly match those of US data, we now show that improvement does not come at the expense of many other business cycle dynamics. Of course, there are dimensions along which the costly entry models under-performs the free entry model and we also describe those. Table 3.2 shows statistics for our sample of U.S. data for selected quantities. We focus on consumption $(C)$, investment $(I)$, unemployment $(U)$, vacancies $(V)$, the vacancies-to-unemployment ratio $(V / U)$, GDP $(Y)$, and total factor productivity $(Z)$. Regarding labor market variables, the two most salient features are: high volatility of unemployment, vacancies, and the vacancies-to-unemployment ratio; and the strong negative correlation between unemployment and vacancies. The first of the two has been the object of a large literature spawned by Shimer's (2005) study, who showed a large discrepancy between the data and traditional models of search and matching in labor markets, for example Pissarides (1985). Subsequently, work by Hagedorn and Manovskii (2009) has shown that an appropriate calibration of the model yields a volatility between the vacancies-to-unemployment ratio and output close to that observed in the data. However, their calibration is still subject to criticism based on the large magnitude of the response of unemployment to minor changes in the level of unemployment benefits (see Hornstein et al. (2005)). Other important facts about labor markets are the weak correlation between vacancies and productivity, the positive correlation between vacancies and output, and the negative correlation between unemployment and output. Other well-known business cycle facts are the lower volatility of consumption and the higher volatility of investment, relative to that of output. Both are highly procyclical. 
Table 3.2: Summary Statistics, Quarterly U.S. Data, 1951:1 to 2003:4

\begin{tabular}{|c|c|c|c|c|c|c|c|c|}
\hline & & C & $I$ & $Y$ & Z & $\bar{V}$ & $\bar{U}$ & $\bar{V} / U$ \\
\hline & $\begin{array}{c}\text { Std. Dev } \\
\text { (rel. to output) }\end{array}$ & 0.526 & 2.984 & 1.00 & 0.590 & 8.635 & 7.778 & 16.073 \\
\hline & Autocorr. & 0.851 & 0.888 & 0.838 & 0.742 & 0.904 & 0.869 & 0.895 \\
\hline \multirow{7}{*}{ Corr. Matrix } & $C$ & 1.000 & 0.692 & 0.780 & 0.195 & 0.728 & -0.649 & 0.705 \\
\hline & $I$ & & 1.000 & 0.865 & 0.360 & 0.832 & -0.727 & 0.799 \\
\hline & $Y$ & & & 1.000 & 0.541 & 0.900 & -0.837 & 0.888 \\
\hline & Z & & & & 1.000 & 0.309 & -0.152 & 0.239 \\
\hline & $V$ & & & & & 1.000 & -0.918 & 0.981 \\
\hline & $U$ & & & & & & 1.000 & -0.977 \\
\hline & $V / U$ & & & & & & & 1.000 \\
\hline
\end{tabular}

Table 3.3 displays the models' standard deviations for some selected variables for three theoretical economies. The first two, labeled the costly entry and the free entry models, are the same economies as those described in previous sections. The third economy is a free entry model calibrated along the lines of Shimer (2005). More specifically, this model has a lower value of unemployment, relative to being employed, and a higher bargaining power for workers. ${ }^{17}$ Compared to the other two models, the free entry model (middle column) matches the data quite well. The degree of amplification is large, and as a result, standard deviations are close to those observed in the data. Nevertheless, in the costly entry model the increases in the standard deviation, relative to the free entry model, are not trivial. Vacancies, unemployment, and the vacanciesto-unemployment ratio all display volatilities that are almost three times those shown by the free entry model with the standard calibration. ${ }^{18}$

To understand the mechanism of amplification in the costly entry model, a standard version of the Pissarides (1985) model is useful. For concreteness, let's take the problem solved by Shimer (2005), which abstracts from capital, firm entry, but features continuous time. Firms and workers search for jobs, and the output of a worker if matched

\footnotetext{
${ }^{17}$ In the appendix we describe the calibration of both free entry economies.

${ }^{18}$ Most results in this paper do not work if we specify a time-varying vacancy posting cost $\omega$. That specification is not equivalent to the costly entry model. However, the time-varying posting cost, if it is countercyclical, causes the volatility of labor market variables to increase, but the persistent dynamics that characterize the costly entry model are absent. Those dynamics improve the behavior of income shares, and that behavior is our main object of study.
} 
Table 3.3: Standard Deviations

\begin{tabular}{cccc}
\hline \hline & Cost. Entry & Free Entry & $\begin{array}{c}\text { Free Entry (low } b / w \\
\text { and high } \phi)\end{array}$ \\
\hline$U$ & 2.872 & 6.736 & 1.245 \\
$V$ & 1.636 & 5.988 & 0.742 \\
$V / U$ & 4.659 & 15.847 & 1.683 \\
$C$ & 1.223 & 0.219 & 0.220 \\
$I$ & 4.570 & 4.413 & 4.739 \\
$Y$ & 1.000 & 1.000 & 1.000 \\
\hline
\end{tabular}

with a firm is $Z$, an exogenous value for productivity that follows a given stochastic process. When workers are looking for a job, they receive unemployment benefits $b$ and the matching mechanism is identical to that of the costly entry model. The dynamics of this economy are represented by the following four equations (where $r$ denotes the discount rate instead of the interest rate and $\theta$ the vacancies-to-unemployment ratio):

$$
\begin{aligned}
r Q & =-\omega+q(\theta)(J-Q), \\
r J & =Z-w-s(J-Q), \\
r W_{u} & =b+f(\theta)\left(W_{e}-W_{u}\right), \\
r W_{e} & =w-s\left(W_{e}-W_{u}\right) .
\end{aligned}
$$

The notation of the value functions follows the costly entry model: $J$ is the value of a filled job, $Q$ is the value of a vacancy, $W_{e}$ is the value of being employed, and $W_{u}$ is the value of being unemployed. To understand the high volatility of labor market variables, it is illustrative to calculate the elasticity of $\theta$ (the vacancies-to-unemployment ratio) to changes in the net labor productivity $Z-b$. Assuming free entry yields $Q=0$ 
in equilibrium, and the elasticity under that case is given by: ${ }^{19}$

$$
\varepsilon_{\theta \mid Z-b}=\frac{r+s+\phi f(\theta)}{(r+s)(1-\eta(\theta))+\phi f(\theta)}
$$

where $\eta(\theta) \in[0,1]$ is the elasticity of $f(\theta)$ with respect to $\theta$. How does this elasticity change if we assume $Q>0$ and if $Q$ is cyclical and varies with $Z$ ? One can show that its value is given by the relatively more complicated expression:

$$
\varepsilon_{\theta \mid \mathrm{Z}-b}=\frac{(r+s+\phi f(\theta)) \Psi+(1-\phi) r q(\theta) Q \Psi}{(r+s)(1-\eta(\theta))+\phi f(\theta)}
$$

where $\Psi=1-(Z-b+\omega) r Q^{\prime}(Z) /(\omega+r Q)$. If $Q^{\prime}(Z)<0$, that is, if $Q$ is countercyclical or responds negatively to changes in $Z$, then $\Psi>1$. Therefore, the elasticity with $Q>0$ is larger than when $Q=0$.

Readers may think about our costly entry model as one in which $Q(Z)$ is an endogenous and complicated object. Its cyclical dynamics are jointly determined with the volume of entrants in the market and the behavior of interest rates. We do not display standard deviations from the costly entry model with low matching efficiency $\xi$, but the volatility of labor market variables in that model is smaller than in the free entry model, even the one calibrated with a high $b / w$. Interest rates are procyclical, making $Q$ procyclical as well. Risking being repetitive, the value of a vacancy $Q$ is countercyclical in the costly entry model because interest rates are countercyclical. Therefore, the mechanism that amplifies the volatility of labor market variables is tightly linked to the mechanism that improves the dynamics of income shares.

Tables 3.4 and 3.5 display correlations between selected variables in the costly entry and the free entry models. Consumption and investment are procyclical in both

\footnotetext{
${ }^{19}$ The equilibrium condition that pins down the value of $\theta$ is given by:

$$
\frac{r+s}{q(\theta)}+\phi \theta=(1-\phi) \frac{Z-b-r Q}{\omega+r Q} .
$$

From this expression, once we have set $Q=0$, it is easy to find the derivative of $\theta$ with respect to $Z-b$.
} 
Table 3.4: Cross Correlations: Costly Entry Model

\begin{tabular}{cccccccc}
\hline \hline & $C$ & $I$ & $V / U$ & $U$ & $V$ & $Y$ & $Z$ \\
$C$ & 1.000 & 0.846 & 0.686 & -0.878 & 0.627 & 0.891 & 0.823 \\
$I$ & & 1.000 & -0.167 & 0.345 & 0.146 & 0.983 & 0.945 \\
$V / U$ & & & 1.000 & -0.882 & 0.907 & -0.005 & 0.138 \\
$U$ & & & & 1.000 & -0.838 & 0.185 & 0.039 \\
$V$ & & & & & 1.000 & 0.317 & 0.455 \\
$Y$ & & & & & & 1.000 & 0.990 \\
$Z$ & & & & & & & 1.000 \\
\hline
\end{tabular}

Table 3.5: Cross Correlations: Free Entry Model

\begin{tabular}{cccccccc}
\hline \hline & $C$ & $I$ & $V / U$ & $U$ & $V$ & $Y$ & $Z$ \\
$C$ & 1.000 & 0.949 & 0.814 & -0.735 & 0.760 & 0.979 & 0.856 \\
$I$ & & 1.000 & 0.791 & -0.889 & 0.795 & 0.993 & 0.982 \\
$V / U$ & & & 1.000 & -0.623 & 0.710 & 0.785 & 0.775 \\
$U$ & & & & 1.000 & -0.511 & -0.899 & -0.843 \\
$V$ & & & & & 1.000 & 0.810 & 0.876 \\
$Y$ & & & & & & 1.000 & 0.987 \\
$Z$ & & & & & & & 1.000 \\
\hline
\end{tabular}

models, with correlations well above 0.70 . The correlation between vacancies and productivity is weaker and closer to the data (0.309) in the costly entry model (0.455) then in the free entry model $(0.876)$. However, we pay a price for this weaker correlation between vacancies and productivity in the form of an acyclical unemployment rate, the biggest drawback of our model. The reason for the acyclical unemployment rate is that vacancies are a predetermined variable, and as a result, the vacancies-tounemployment ratio is not very cyclical. Therefore employment is not very cyclical. However, the costly entry model shows a stronger correlation between vacancies and unemployment (the slope of the Beveridge curve) than the model with free entry. The reason is that in the costly entry model, vacancies do not react immediately to changes in productivity: existing firms that separate from their workers do no repost vacancies; entrants need to wait for one period and pay $y^{E}$ before posting them. As a result, vacancies and unemployment move closer to one-to-one than in the free entry envi- 
ronment, where vacancies immediately adjust to changes in productivity but unemployment does not. Finally, costly entry has an effect on the persistence of shocks over time. Table 3.6 displays the first four autocorrelations for the same variables as those in Tables 3.4 and 3.5. Even though investment is less persistent in the costly entry model, labor market variables, in particular vacancies and the vacancies-to-unemployment ratio, become more correlated over time. ${ }^{20}$ In particular, regarding the persistence of vacancy creation, these results confirm the findings of Fujita and Ramey (2007).

Table 3.6: Autocorrelations

\begin{tabular}{cccccc}
\hline \hline & & 1 & 2 & 3 & 4 \\
\hline \multirow{4}{*}{$C$} & Costly Entry & 0.805 & 0.557 & 0.348 & 0.175 \\
& Free Entry & 0.813 & 0.575 & 0.370 & 0.200 \\
& Costly Entry & 0.738 & 0.446 & 0.223 & 0.053 \\
& Free Entry & 0.880 & 0.686 & 0.480 & 0.283 \\
& Costly Entry & 0.958 & 0.852 & 0.707 & 0.539 \\
$V / U$ & Free Entry & 0.728 & 0.416 & 0.178 & 0.004 \\
& Costly Entry & 0.960 & 0.856 & 0.709 & 0.539 \\
$U$ & Free Entry & 0.943 & 0.802 & 0.615 & 0.414 \\
& Costly Entry & 0.923 & 0.777 & 0.611 & 0.439 \\
$V$ & Free Entry & 0.715 & 0.392 & 0.153 & -0.017 \\
& Costly Entry & 0.759 & 0.474 & 0.249 & 0.076 \\
$Y$ & Free Entry & 0.845 & 0.625 & 0.415 & 0.226 \\
\hline
\end{tabular}

\section{Final Remarks}

We have constructed a quantitative model of the macroeconomy that is consistent with most income shares' time series facts. The novel aspect of our environment relative to models with frictional labor markets is to assume costly entry by firms. This assumption introduces cyclical dynamics in the asset value of a vacant position, a value which in equilibrium has to equal the expenditures undertaken by firms to enter production markets. For the model to account for income shares' dynamics and to propagate and

\footnotetext{
${ }^{20}$ Of course, the autocorrelation of shocks is the same across the two models.
} 
amplify productivity shocks, the asset value of a vacancy has to be negatively correlated with output over the business cycle. In our framework, interest rates have to be negatively correlated. This negative correlation of real interest rates and output has proven difficult to obtain in production economies.

Although the framework can account for many time series facts regarding labor markets and income shares times, work remains to be done. For instance, labor's share seems to have a high volatility at lowfrequencies but a low volatility at high frequencies. This translates to a large and persistent response of that share to changes in productivity. The cyclical component of labor's share is smoother than output. These two facts are difficult to reconcile with the type of model we have presented and call for further research to account for low-frequency movements in income shares of a different nature than the high frequency movements observed between expansions and recessions. 


\section{References}

[1] Bilbiie, F. O., Ghironi, F. and Melitz, M.J.: 2006, “Endogenous Entry, Product Variety, and Busines Cycles," manuscript, Boston College.

[2] Basu, S. and J. G. Fernald: 1997, "Returns to Scale in U.S. Production: Estimates and Implications," Journal of Political Economy 105, 249-283.

[3] Blanchard, O. and P. Diamond: 1989, "The Beveridge Curve," Brookings Papers in Economic Activity, Vol. 1, pp. 1-60.

[4] Boldrin, M. and M. Horvath: 1995, “Labor Contracts and Business Cycles," Journal of Political Economy, Vol. 103, No. 5, pp. 972-1003.

[5] Danthine, J. P. and J. Donaldson: 1992, "Risk-Sharing in the Business Cycle," European Economic Review, Vol. 36, pp. 469-75.

[6] Davis, S. J., J. C. Haltiwanger, and S. Schuh: 1996, Job Creation and Destruction. MIT Press.

[7] Davis, S., J. Faberman, and John C. Haltiwanger: 2008, “The Establishment-Level Behavior of Vacancies and Hiring," manuscript.

[8] Den Haan, W. J., G. Ramey, and J. Watson: 2000, “Job Destruction and Propagation of Shocks," American Economic Review 90(3), 482-498.

[9] Dixit, A. K. and J. E. Stiglitz: 1977, “Monopolistic Competition and Optimum Product Diversity". American Economic Review 67, 297-308.

[10] Feenstra, R.: 2003, “A Homothetic Utility Function for Monopolistic Competition Models without Constant Price Elasticity," Economics Letters 78, pp. 79-86.

[11] Fujita, S. and G. Ramey: 2006,“Job Matching and Propagation," Journal of Economic Dynamics and Control 31(11): 3671-3698. 
[12] Gertler, M. and A. Trigari: 2009,“Unemployment Fluctuations with Staggered Nash Wage Bargaining," Journal of Political Economy, Vol. 117(2), pp. 38-86.

[13] Gomme, P., B. Ravikumar and P. Rupert: in press, “The Return to Capital and the Business Cycle," Review of Economic Dynamics.

[14] Gomme, P. and J. Greenwood: 1995,“On the Cyclical Allocation of Risk,” Journal of Economic Dynamics and Control 19:91-124.

[15] Hagedorn, M. and I. Manovskii: 2008, “The Cyclical Behavior of Equilibrium Unemployment and Vacancies Revisited," American Economic Review, 98(4), pp. 16921706.

[16] Hornstein, A. :1993, “Monopolistic Competition, Increasing Returns to Scale, and the Importance of Productivity Shocks," Journal of Monetary Economics, 31(3), pp. 299-316.

[17] Hornstein, A., P. Krusell and G. Violante :2005, “Unemployment and Vacancy Fluctuations in the Matching Model: Inspecting the Mechanism," Federal Reserve Bank of Richmond Economic Quarterly, Vol. 91/3.

[18] King, R. G. and S. Rebelo: 1999, "Resuscitating Real Business Cycles," in Taylor, J.B., and M. Woodford, eds., Handbook of Macroeconomics, vol. 1B, 927-1007, Elsevier, Amsterdam.

[19] Pissarides, C.: 1985, "Short-Run Equilibrium Dynamics of Unemployment, Vacancies, and Real Wages," American Economic Review 75(4), pp. 676-690.

[20] Pissarides, C.: 2000, “Equilibrium Unemployment Theory", MIT Press, Cambridge, MA.

[21] Ríos-Rull, J.V. and R. Santaeulalia-Llopis: 2007,"Redistributive Shocks and Productivity Shocks," manuscript, University of Minnesota. 
[22] Ríos-Rull, J.V. and S. Choi: 2008, “Understanding the Dynamics of Labor Share: The Role of Non-Competitive Factor Prices". University of Minnesota.

[23] Rogerson, R., R. Shimer and R. Wright: 2005, "Search-Theoretic Models of the Labor Market: A Survey," Journal of Economic Literature 43(4):959-988.

[24] Shimer, R.: 2005, “The Cyclical Behavior of Equilibrium Unemployment and Vacancies," American Economic Review 95(1), 25-49.

[25] Stock, J. and M. Watson: 1999a, "Business Cycle Fluctuations in U.S. Macroeconomic Time Series," in Taylor, J.B., and M. Woodford, eds., Handbook of Macroeconomics, vol. 1A, 3-64, Elsevier, Amsterdam.

[26] Stock, J. and M. Watson: 1999b, "Forecasting Inflation," Journal of Monetary Economics, Vol. 44, no. 2.

[27] Young, A.: 2004, “Labor's Share Fluctuations, Biased Technical Change, and the Business Cycle," Review of Economic Dynamics, Vol. 7, pp 916-931. 


\section{A Appendix: The Free-Entry Model}

For the sake of exposition we briefly describe the free entry model (Pissarides (1985) and Shimer (2005)). This model serves as a benchmark framework for many of the results in the text.

The economy is populated by a large household of measure one. Members of the household can be either employed or unemployed. Denote the fraction of those employed at time $t$ by $N_{t}$. The household's preferences are given by,

$$
E_{0} \sum_{t=0}^{\infty} \beta^{t}\left[\frac{\left(C_{t}\right)^{1-\sigma}}{1-\sigma}\right]
$$

A general good $Y$ is produced using capital $K$ and labor $N$ by a single firm employing the following technology,

$$
Y=Z K^{\alpha} N^{1-\alpha}
$$

$Z$ represents technology (TFP) that evolves according to:

$$
\log \left(Z_{t}\right)=\rho \log \left(Z_{t-1}\right)+\epsilon_{t}
$$

The innovation $\epsilon_{t}$ is i.i.d. The labor market is characterized by search and matching frictions. Unemployed workers search, and firms post vacancies. It costs $\omega$ to post one vacancy, and workers and firms match according to the following matching technology,

$$
M(1-N, V)=\frac{(1-N) V}{\left((1-N)^{\xi}+V^{\xi}\right)^{\frac{1}{\xi}}}
$$

The household owns shares in the firm obtaining profits equal to $\pi_{t}$. As a result, the firm discounts the future (between any period $t$ and $t+1$ ) using the intertemporal marginal rate of substitution of the household: $\beta\left(\frac{C_{t+1}}{C_{t}}\right)^{-\sigma}$. The equilibrium value of a vacancy is zero, as firms will enter until there are no gains made by posting them. We denote by $q$ the probability that a firm fills a vacancy, by $s$ the rate at which existing 
matches between workers and firms separate, and by $J$ the capital value of a filled job. In equilibrium,

$$
\omega=q_{t} \beta\left(\frac{C_{t+1}}{C_{t}}\right)^{-\sigma} J_{t+1}
$$

and

$$
J_{t}=\pi_{t}+\beta\left(\frac{C_{t+1}}{C_{t}}\right)^{-\sigma} J_{t+1}(1-s) .
$$

We assume wages are negotiated through Nash bargaining, in which firms have a bargaining weight equal to $\phi$. Wages are the solution to the following surplus splitting rule,

$$
\frac{J_{t}}{1-\phi}=\frac{C_{t}^{\sigma} \frac{\partial W_{t}}{\partial N_{t}}}{\phi}
$$

The interpretation of this expression is analogous to that of the text. As vacancies have zero value in equilibrium the threat point for the firm is zero. The threat point for the representative household, is given by the marginal disutility of having one more member unemployed. Finally, the aggregate resource constraint equates total goods produced, net of vacancy creation costs, to the sum of investment and consumption:

$$
Y_{t}-\omega V_{t}=C_{t}+I_{t} .
$$

Table A.1 summarizes our parameterization of the free entry model. We keep the targets for the calibration the same as in the costly entry model to ease comparisons. The only exception to this approach is the target for the ratio of unemployment benefits to wages. This ratio is set to 0.426 in the costly entry model and to 0.95 in the free entry model. In the spirit of the parameterization used by Hagedorn and Manovskii (2010) we also decrease the bargaining weight $\phi$ to a value of 0.1 . Both of these features are responsible for the large amplification mechanism. Table A.2 displays the parameterization of the model labeled "free entry with low $b / w$ and high $\phi$ ". This alternative parameterization is the result of setting $\phi$ to 0.5 and calibrating $b / w$ to be 0.426 . It is roughly consistent with the one used by Shimer (2005). 
Table A.1: Summary of Parameterization (Free Entry)

\begin{tabular}{cc} 
Parameter & Value \\
\hline \hline & \\
$\phi$ & 1.500 \\
$\rho_{z}$ & 0.100 \\
$\sigma_{z}$ & 0.964 \\
$s$ & 0.005 \\
$\beta$ & $(0.99)^{\frac{1}{3}}$ \\
$\delta$ & 0.005 \\
$b$ & 3.016 \\
$\omega$ & 2.410 \\
$\xi$ & 1.172 \\
$\alpha$ & 0.300 \\
\hline
\end{tabular}

Table A.2: Summary of Parameterization (Free Entry with low $b / w$ and high $\phi$ )

\begin{tabular}{cc} 
Parameter & Value \\
\hline \hline$\sigma$ & 1.500 \\
$\phi$ & 0.5 \\
$\rho_{z}$ & 0.964 \\
$\sigma_{z}$ & 0.005 \\
$s$ & 0.019 \\
$\beta$ & $(0.99)^{\frac{1}{3}}$ \\
$\delta$ & 0.005 \\
$b$ & 1.353 \\
$\omega$ & 3.112 \\
$\xi$ & 2.375 \\
$\alpha$ & 0.30 \\
\hline
\end{tabular}

